
$\begin{array}{ll}\text { Submission: } 20 / \mathrm{Feb} / 2021 ; & 1^{\text {st }} \text { round notif.: } 05 / \mathrm{May} / 2021 ; \\ \text { Camera ready: } 15 / \mathrm{Jul} / 2021 ; & \text { Edition review: } 20 / \mathrm{Jul} / 2021 ;\end{array}$
New version: 02/Jun/2021; Available online: 06/Aug/2021; $2^{\text {nd }}$ round notif.: $29 / \mathrm{Jun} / 2021$; Published: 06/Aug/2021;

\title{
A Participação Feminina nos Cursos Técnicos Integrados ao Ensino Médio da Educação Profissional e Tecnológica
}

\author{
Title: Female Participation in Technical Courses Integrated to High School Professional and \\ Technological Education
}

\author{
Thamiris Stephane Zangeski Novais Paiva \\ Instituto Federal de Mato Grosso \\ Campus Cuiabá - Cel. Octayde Jorge da Silva \\ Programa de Pós-Graduação do Mestrado Profissional \\ em Educação Profissional e Tecnológica-ProfEPT. \\ thamiris.tutora@gmail.com
}

\author{
Juliana Saragiotto Silva \\ Instituto Federal de Mato Grosso \\ Campus Cuiabá - Cel. Octayde Jorge da Silva \\ Programa de Pós-Graduação do Mestrado Profissional \\ em Educação Profissional e Tecnológica-ProfEPT. \\ juliana.silva@cba.ifmt.edu.br
}

\begin{abstract}
Resumo
Historicamente, as mulheres foram relegadas a papel de cuidadoras, reprodutoras e mantenedoras da vida na esfera doméstica. Inclusive, por muito tempo, a educação da mulher foi pautada na incorporação das Ciências relacionadas ao cuidado, em detrimento das Ciências Exatas. Atualmente, estudos demonstram o aumento da escolaridade das mulheres frente aos homens; entretanto, as mulheres continuam sendo minoria em algumas áreas do conhecimento, que, no senso comum, são destinadas aos homens. Deste modo, o objetivo desta pesquisa foi investigar a representação feminina em alguns cursos técnicos integrados ao Ensino Médio, da Educação Profissional e Tecnológica (EPT), ofertados pelo Instituto Federal de Mato Grosso - Campus Cuiabá, Cel. Octayde Jorge da Silva, no período de 2010 a 2019. Após definido o lócus do estudo, procedeu-se à coleta de dados, em duas fases. Na primeira, foram angariadas as listagens de matrículas de estudantes dos cursos, no sistema "Q-Acadêmico" do Campus. Na segunda, foram coletados, na Plataforma Nilo Peçanha, os dados referentes à concentração feminina no lócus da pesquisa e nos demais Institutos Federais do Brasil, entre os anos de 2017 e 2019. A partir da análise e discussão dos dados, percebeu-se que a representatividade feminina, nos cursos pesquisados, foi inferior à masculina. Este fato contrapõe outras pesquisas que demonstram que, no Brasil, as matrículas na EPT vêm sendo ocupadas, majoritariamente, por mulheres. Além disso, verificou-se que as taxas de evasão feminina são menores que a masculina e que as taxas de conclusão de curso são maiores. Conclui-se assim, que apesar de as meninas terem maior representatividade na EPT em nível nacional, no recorte desta pesquisa, este fato não se repetiu.
\end{abstract}

Palavras-Chave: Estudo de gênero; meninas; Ciência e Tecnologia.

\begin{abstract}
Historically, women have been relegated to the role of caregivers, breeders, and maintainers of life in the domestic sphere. Even, for a long time, women's education was based on the incorporation of sciences related to care, to the detriment of the Exact Sciences. Currently, studies show the increase in women's education in relation to men; however, women continue to be a minority in some areas of knowledge, which, in common sense, are directed at men. Thus, the objective of this research was to investigate the female representation in some technical courses integrated to high school, Professional and Technological Education (PTE), offered by the Federal Institute of Mato Grosso - Campus Cuiabá, Col. Octayde Jorge da Silva, from 2010 to 2019. After the locus of the study was defined, data were collected in two phases. In the first, the student enrollment listings of the courses were collected in the "Q-Acadêmico" system of the Campus. In the second, data were collected, on the Nilo Peçanha Platform, regarding female concentration in research locus and in other Federal Institutes of Brazil, between 2017 and 2019. From the analysis and discussion of the data, it was noticed that the female representativeness in the courses researched, was lower than the male one. This fact contradicts other studies that show that, in Brazil, enrollment in PTE has been occupied, mostly, by women. In addition, it was found that female dropout rates are lower than male

Cite as: Paiva, T. S. Z. N., \& Silva, J. S. (2021). A Participação Feminina nos Cursos Técnicos Integrados ao Ensino Médio da Educação Profissional e Tecnológica. Revista Brasileira de Informática na Educação, 29, 993-1006. DOI: 10.5753/RBIE.2021.29.0.993
\end{abstract}


and that the completion rates are higher. Thus, although girls had greater representation in PTE at the national level, in the study, this fact was not repeated.

Keywords: Gender study, girls; Science and Technology.

\section{Introdução}

A história demonstra, que por muito tempo, as mulheres foram preteridas socialmente às funções de cuidadoras, reprodutoras e mantenedoras da vida na esfera privada. Por conta deste modelo de sociedade patriarcal, a baixa escolaridade feminina também era comum. De acordo com Louro (2004), no início do século XIX, no Brasil, foram criadas nas cidades e vilarejos mais populosos do Império as "Escolas de primeiras letras", com o objetivo de diminuir o analfabetismo da população. Apesar das operações básicas e a educação cristã serem ofertadas às crianças de ambos os sexos, os meninos eram contemplados com disciplinas de Geometria e, as meninas, aprendiam bordado e costura.

Neste sentido, percebe-se que esta exclusão feminina impactou no desenvolvimento do campo da Ciência e Tecnologia (C\&T), que foi destinado e ocupado, majoritariamente, por homens. Isto ocorreu em função de discursos científicos que postulavam que, por determinações biológicas, a mulher seria menos capaz de produzir Ciência e Tecnologia que o homem (Freitas \& Luz, 2017).

Apesar deste histórico, as autoras García e Sedeño (2002) apontam que a presença feminina na C\&T não foi tão baixa como se imagina. Para as autoras, a representação feminina foi invisibilizada por preconceitos e concepções ultrapassadas do que é a história da Ciência e da Tecnologia. Exemplo disso é que as mulheres sempre estiveram à frente dos conhecimentos em diversas Ciências como a Botânica e a Medicina, em especial na Ginecologia e Obstetrícia, que eram praticadas, exclusivamente, por elas. Porém, a datar do século XIII, estes conhecimentos foram institucionalizados, após a criação de faculdades de Medicina e Educação Médica Formal nas universidades, o que resultou na exclusão feminina dessas áreas (García, 2018). Outro exemplo do apagamento histórico de mulheres cientistas é o caso de Ada Lovelace (1815 1852), uma matemática e escritora, que criou o primeiro algoritmo para computador da história. Apesar disso, somente mais de cem anos após sua morte é que ela foi reconhecida pelo seu feito.

Diante do exposto, percebe-se que as mulheres sempre fizeram Ciência, mas foram silenciadas e invisibilizadas. Tanto que, García (2018) afirma que são muitos os mecanismos implícitos de discriminação e segregação que atuam para manter essas desigualdades de gênero.

Neste sentido, Saavedra (2009) aponta que o número de meninos e meninas que se interessam por Ciências, Engenharias e Tecnologias costuma ser o mesmo até os doze e treze anos de idade. A partir destas idades, os dados apontam para uma queda do número de meninas que escolhem estas áreas, em todos os níveis de ensino seguintes. Além disso, a falta de um modelo inspiracional, de mulheres atuando nestas áreas, contribui para este afastamento.

No Brasil, existe a modalidade de Ensino Médio integrado à Educação Profissional (ensino técnico). De acordo com Kunze (2009), esta modalidade de ensino foi criada em 1909, com o objetivo de profissionalizar o povo (no caso, os homens), de forma a gerar mais incentivos ao trabalho e à mão de obra nas indústrias, que começavam a surgir no país, no início do século XX.

Segundo o Instituto Nacional de Estudos e Pesquisas Educacionais Anísio Teixeira (Inep, 2020a), no ano de 2018, 52,7\% dos estudantes da Educação Profissional e Tecnológica (EPT) estavam matriculados em cursos técnicos integrados ao Ensino Médio e 47\% em cursos técnicos subsequentes. Outrossim, o Brasil é o país com menor percentual de atendimento à população 
jovem (15 a 24 anos) em programas de EPT, com taxa menor que 5\%, sendo a Eslovênia o país com maior taxa de participação jovem - acima de $30 \%$.

Fazendo-se um recorte de gênero, percebe-se que, entre 2013 e 2019, as matrículas na EPT foram ocupadas, majoritariamente, por mulheres em todos os anos, com taxa média de 55,9\% e com tendência de crescimento desde 2016 (Inep, 2020b). Especificamente, no estado de Mato Grosso, a representação feminina é de 52,2\% (Inep, 2020c).

Diante deste contexto, justifica-se investigar a presença feminina no Ensino Médio da EPT por considerar que esta fase representa um marco na vida das estudantes. Inclusive, Saavedra (2009) afirma que, uma das primeiras responsabilidades atribuídas aos jovens, na atualidade, é a escolha da formação e carreira. Não obstante, o gênero é a barreira que mais limita a liberdade dos jovens para fazer estas escolhas. Por conta das influências socioculturais, percebe-se a existência de estereótipos de gênero nas carreiras, que demarcam as que são adequadas para os homens e as que são adequadas para as mulheres. Isto faz com que meninas e mulheres evitem, por exemplo, as Ciências Exatas e as Tecnologias, bem como, os cursos relacionados a essas áreas, como a Informática e as Engenharias.

Deste modo, o objetivo desta pesquisa foi investigar a representação feminina nos seguintes cursos técnicos do Ensino Médio Integrado (EMI) da EPT: Agrimensura, Edificações, Eletroeletrônica e Informática, ofertados pelo Instituto Federal de Mato Grosso - Campus Cuiabá - Cel. Octayde Jorge da Silva; no período de 2010 à 2019.

Para tanto, este artigo está estruturado em 5 seções, incluindo esta Introdução. Na seção 2 discute-se, brevemente, alguns trabalhos relacionados. Na sequência, na seção 3 é descrita a metodologia aplicada e, na seção 4, são apresentados os resultados e discussões sobre os achados da pesquisa. Por fim, na seção 5 faz-se as considerações finais.

\section{Trabalhos Relacionados}

Estudos sobre a representatividade feminina em cursos técnicos profissionalizantes, sobretudo os do Ensino Médio, ajudam a mapear as áreas de maior e menor concentração feminina e têm potencial de corroborar para diagnosticar as desigualdades de gênero que podem impactar, diretamente, nas escolhas femininas de formação e carreira. Além do mais, conseguem contribuir para o debate e a criação de propostas para mitigar essas desigualdades.

No Brasil, pesquisas sobre mulheres nas áreas da C\&T, em especial no Ensino Médio Técnico, ainda são incipientes. Inclusive, dos cursos objetos de pesquisa deste artigo, só foram encontrados estudos pontuais sobre a presença feminina no curso Técnico em Informática. Ademais, percebe-se uma carência destes estudos em cursos técnicos relacionados com a área das Engenharias.

As iniciativas da Sociedade Brasileira de Computação (SBC) como o workshop "Women in Information Technology" (WIT) e o programa "Meninas Digitais" ${ }^{2}$ discutem os assuntos relacionados às questões de gênero, principalmente na área de Tecnologia da Informação (TI), buscando despertar o interesse de meninas para seguirem carreira em Tecnologia da Informação e Comunicação. O Sistema CONFEA (Conselho Federal de Engenharia e Agronomia)/CREA (Conselho Regional de Engenharia e Agronomia) e Mútua (Caixa de Assistência aos Profissionais) reconhece no "Programa Mulher" a necessidade de promover e estimular a equidade de gênero dentro do Sistema e entidades de classe, visando ampliar a participação das mulheres de forma protagonista na área (CONFEA, 2021).

\footnotetext{
${ }^{1}$ Informações adicionais sobre este evento estão disponíveis em: https://csbc.ufsc.br/eventos/wit/.

${ }^{2}$ Detalhes adicionais estão disponíveis em: http://meninas.sbc.org.br/sobre/.
} 
Ademais, trabalhos como os de Lopes e Quirino (2017) e Marinho, Fagundes e Aguilar (2019), que tinham como escopo desvelar dados quantitativos sobre gênero na Educação, apontaram que a representação feminina, em cursos das áreas da $\mathrm{C} \& \mathrm{~T}$, foi inferior à masculina.

Desta forma, para além de uma análise quantitativa, buscou-se identificar alguns estudos com análise qualitativa, que ampliassem a compreensão dos motivos dessa desigualdade. Como exemplo deste tipo de análise, o estudo de Pereira et al. (2020) demonstra que as estudantes do curso de Ciência da Computação possuem um desempenho escolar melhor, porém revelam a ansiedade para a manutenção deste desempenho. Já as estudantes do curso Técnico em Informática apresentaram certo grau de desestabilidade emocional e timidez, ao longo do curso, e, em função disso, a maioria mencionou que não pretende cursar o nível superior na área de Tecnologia da Informação - o que dificultou o processo de verticalização do ensino, neste contexto.

Nesta mesma direção, Ribeiro e Maciel (2020) afirmam que, ingressar no curso Técnico em Informática não é suficiente para a verticalização do ensino. Para os autores, existem fatores que influenciam a autoeficácia e os interesses das estudantes na área, as suas escolhas de carreira e suas expectativas de resultado. Deste modo, os fatores identificados podem aproximá-las ou afastá-las de persistirem em uma formação de nível Superior na área de Computação, dependendo de como esses fatores estão colocados na vida delas.

Outro trabalho relacionado, de Lopes e Quirino (2017), elucida que as alunas do Curso Técnico em Mecânica demonstraram que a influência familiar aparece, de forma mais evidente, na opção pela verticalização do ensino. Já Santana, Assis, Braga e Louzada (2017) ressaltam a importância de atividades para o empoderamento feminino nos cursos de TI, de forma a minimizar a evasão e incentivar a verticalização do ensino.

Com base nos estudos citados, depreende-se que a produção do conhecimento sobre gênero nas áreas da C\&T é fortalecida por iniciativas organizacionais, como as da SBC. Apesar disso, ainda há poucos estudos, com recorte de gênero, que se aprofundem na compreensão da representação feminina em cursos, que historicamente, foram ocupados, em sua maioria, por homens.

Posto isto, na próxima seção, são demonstrados os aspectos metodológicos adotados na realização desta pesquisa.

\section{Metodologia}

O lócus para a realização desta pesquisa foi o IFMT - Campus Cuiabá - Cel. Octayde Jorge da Silva, pois, neste local, estão concentrados alguns cursos técnicos voltados para as Ciências Exatas e Engenharias que, tradicionalmente, possuem uma representatividade feminina menor. Além do mais, o IFMT tem o objetivo de melhorar o ensino de Ciências e atrair jovens para carreiras na área de C\&T (IFMT, 2018). Desta forma, esta pesquisa poderá corroborar para que tanto a instituição IFMT, como sua comunidade, possam refletir acerca desta temática.

Neste artigo, são utilizados os dados de uma das etapas da pesquisa de mestrado ${ }^{3}$, em andamento, das autoras. Deste modo, a investigação se iniciou a partir de uma revisão bibliográfica, para a construção do aporte teórico, contemplado pelas temáticas de gênero e Educação Profissional e Tecnológica. Já a coleta e o tratamento dos dados foram realizados em duas fases: coleta de dados do sistema e organização das variáveis de análise.

\footnotetext{
${ }^{3}$ Mestrado em Educação Profissional e Tecnológica (ProfEPT). Linha de pesquisa: Práticas Educativas em Educação Profissional e Tecnológica.
} 
$\mathrm{Na}$ primeira fase, foram coletadas as listagens de matrículas de estudantes dos cursos técnicos em Agrimensura, Edificações, Eletroeletrônica e Informática, entre os anos de 2010 e 2019. Em seguida, os dados foram categorizados por curso, ano e gênero. Na sequência, os dados foram separados nas seguintes variáveis: (i) Ano letivo inicial - para saber o quantitativo de ingressos por ano; (ii) Ano letivo atual - para verificar a quantidade de matriculados em cada ano; (iii) Sexo; e (iv) Situação da matrícula - para distinguir "concluído", "evasão" e "transferido".

Vale destacar que o sistema "Q-Acadêmico" possui diferentes termos para a classificação da situação da matrícula dos estudantes. Desta forma, para a caracterização da evasão de curso, nesta pesquisa, foram agrupadas as seguintes situações de matrícula: cancelada, evasão, transferência externa e transferência interna. Por conseguinte, realizou-se a contagem de alunas presentes no conjunto das variáveis elencadas e realizou-se a análise estatística dos dados.

Além disso, verificou-se que os cursos, objetos desta pesquisa, possuem tempos de duração distintos. Dado que, os cursos técnicos em Agrimensura e Edificações possuem duração de 4 anos e, os cursos técnicos em Eletroeletrônica e Informática, possuem duração de 3 anos. Sendo assim, a análise e demonstração dos indicadores de evasão e conclusão foram realizadas tendo como referência o ano de ingresso das alunas, ou seja, verificou-se o total de ingressantes em um determinado curso e ano e, com base neste quantitativo, calculou-se quantas estudantes evadiram e quantas concluíram.

$\mathrm{Na}$ segunda fase, foram coletados os dados da Plataforma Nilo Peçanha (MEC, 2020), referentes à concentração feminina nos Eixos Tecnológicos ${ }^{4}$ (ET) dos cursos técnicos integrados ao Ensino Médio, dos Institutos Federais. Estes dados compreendem o período de 2017 a 2019 e foram consultados, mediante a aplicação dos seguintes filtros de busca: selecionou-se a guia "1.6 Sexo e Faixa Etária"; depois, na variável "Organização Acadêmica", escolheu-se a opção "Instituto Federal"; na variável "Tipo de curso", selecionou-se a opção "Técnico"; sobre o "Tipo de oferta", marcou-se o "Integrado". Posteriormente, foi intercalando-se as opções de "Eixos Tecnológicos" e "Nomes dos Cursos".

Com base nos dados coletados, produziu-se um comparativo dos indicadores da participação feminina no Campus Cuiabá - Cel. Octayde Jorge da Silva com os de âmbito nacional, conforme apresentado a seguir.

\section{Análise e Discussão dos Dados}

Esta seção é dedicada à análise e discussão dos dados coletados acerca do ingresso, interrupção e conclusão de curso das estudantes do Ensino Médio Técnico, dos cursos objetos da pesquisa.

\subsection{Sobre o Ingresso Feminino nos Cursos}

Ao se investigar os dados de ingresso percebe-se que, em geral, a representatividade feminina nos cursos foi inferior à masculina (Gráfico 1). Inclusive, agregando-se os dados referentes aos quatro cursos e considerando os seus diferentes períodos de funcionamento, obtém-se uma média geral de $33 \%$ de ingresso feminino.

\footnotetext{
4 "É o agrupamento de ações e das aplicações científicas às atividades humanas de mesma natureza, possuindo um núcleo de saberes comuns, embasados nas mesmas Ciências e metodologias. São aplicados na classificação dos cursos da educação profissional, constante dos Catálogos Nacionais” (MEC, 2020, p. 6).
} 


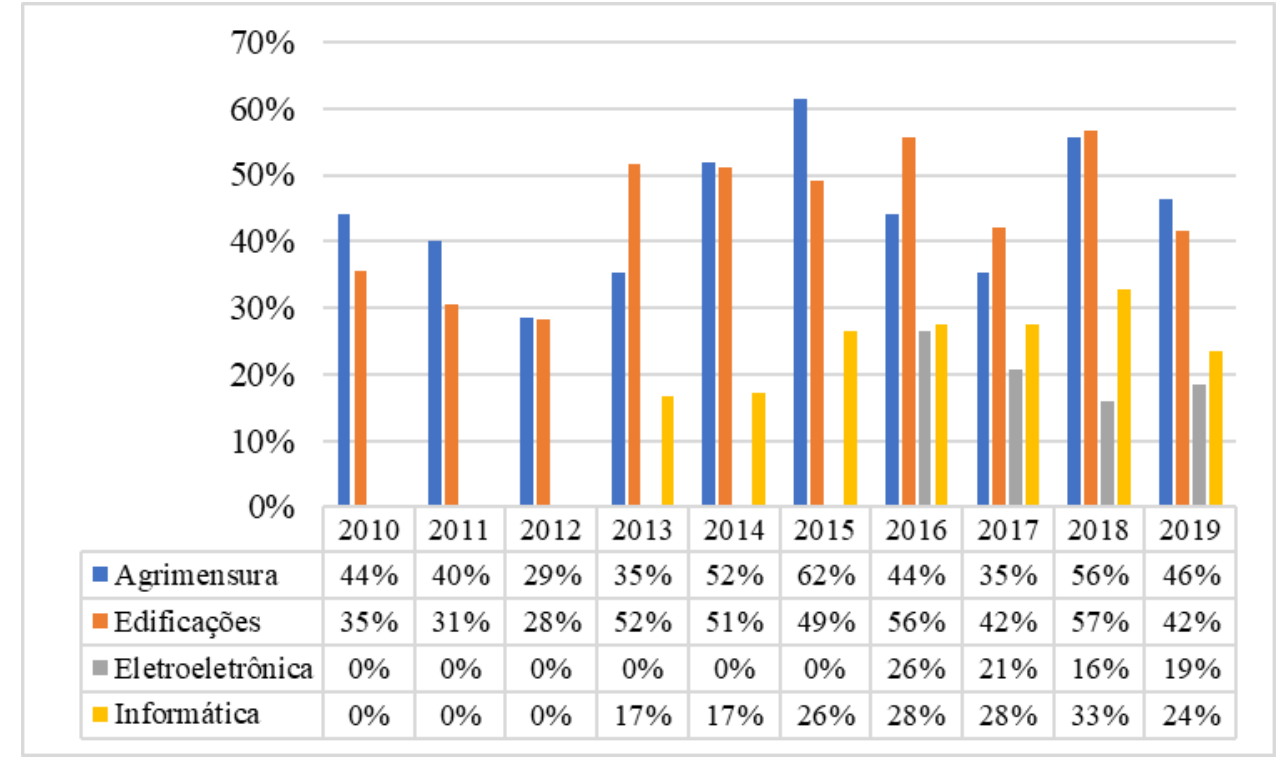

Gráfico 1- Ingresso feminino anual (2010-2019) no IFMT - Campus Cuiabá - Cel. Octayde Jorge da Silva Notas:

(1) Não houve registros de turmas ingressantes nos cursos de Eletroeletrônica, entre os anos de 2010 e 2015, nem de Informática, entre os anos de 2010 e 2012.

(2) Para saber a representação masculina basta calcular o percentual de ingresso restante.

Por conseguinte, ao se explorar os cursos, individualmente, pôde-se verificar que Agrimensura e Edificações foram os cursos que apresentaram maior representatividade feminina, se comparados aos outros dois. Além disso, os ingressos, em alguns anos analisados, foram predominantemente femininos. Ainda com relação aos cursos técnicos em Agrimensura e Edificações, observou-se que a taxa média de ingresso feminino, dos dois cursos, para os dez anos analisados, foi de $44 \%$.

Já os cursos técnicos em Eletroeletrônica e Informática foram os que demonstraram maior disparidade na representação por gênero, visto que a participação feminina foi menor, em todos os anos analisados. Percebeu-se também, que o curso Técnico em Eletroeletrônica foi o curso com menor ocupação feminina, com taxa média de ingresso de $20 \%$, seguido do Técnico em Informática, que foi de $25 \%$. Ainda assim, foi possível identificar que, com exceção do curso Técnico em Eletroeletrônica, todos os outros cursos analisados apresentaram expansão no ingresso feminino, se comparados o primeiro e o último ano de oferta.

Dessa forma, para compreender melhor a representação feminina no Campus, consultou-se, também, as estatísticas oficiais presentes na Plataforma Nilo Peçanha (MEC, 2020), nos anos base de 2017 a 2019. Com isso, percebeu-se que a desigualdade na concentração feminina, encontrada nos cursos pesquisados, está relacionada com os seus ETs, conforme demonstrado na Tabela 1.

De antemão, é preciso evidenciar que os Eixos Tecnológicos da Rede Federal de Educação, são compostos por diversos cursos, de diferentes níveis e tipos. Desta forma, neste comparativo, foram utilizados apenas os dados dos cursos técnicos, objetos da pesquisa. 
Tabela 1 - Concentração feminina, por ET, no IFMT, Campus Cuiabá - Cel. Octayde Jorge da Silva (2017 a 2019)

\begin{tabular}{|c|c|c|c|c|c|c|c|}
\hline \multirow[b]{2}{*}{ Eixo Tecnológico } & \multirow[b]{2}{*}{ Curso Técnico } & \multicolumn{2}{|c|}{2017} & \multicolumn{2}{|c|}{2018} & \multicolumn{2}{|c|}{2019} \\
\hline & & $\begin{array}{l}(\%) \text { por } \\
\text { ET }\end{array}$ & $\begin{array}{c}(\%) \text { no } \\
\text { EMI }\end{array}$ & $\begin{array}{l}(\%) \text { por } \\
\text { ET }\end{array}$ & $\begin{array}{c}(\%) \text { no } \\
\text { EMI }\end{array}$ & $\begin{array}{l}(\%) \text { por } \\
\text { ET }\end{array}$ & $\begin{array}{c}(\%) \text { no } \\
\text { EMI }\end{array}$ \\
\hline $\begin{array}{l}\text { Turismo, Hospitalidade e } \\
\text { Lazer }\end{array}$ & Eventos & $79 \%$ & \multirow{9}{*}{$47 \%$} & $81 \%$ & \multirow{9}{*}{$49 \%$} & $85 \%$ & \multirow{9}{*}{$48 \%$} \\
\hline Gestão e Negócios & Secretariado & $78 \%$ & & $78 \%$ & & $80 \%$ & \\
\hline \multirow{2}{*}{ Infraestrutura } & Agrimensura* & \multirow{2}{*}{$42 \%$} & & \multirow{2}{*}{$46 \%$} & & \multirow{2}{*}{$45 \%$} & \\
\hline & Edificações* & & & & & & \\
\hline \multirow{2}{*}{$\begin{array}{l}\text { Informação e } \\
\text { Comunicação }\end{array}$} & Informática* & \multirow{2}{*}{$29 \%$} & & \multirow{2}{*}{$32 \%$} & & \multirow{2}{*}{$26 \%$} & \\
\hline & Telecomunicações & & & & & & \\
\hline \multirow{3}{*}{$\begin{array}{l}\text { Controle e Processos } \\
\text { Industriais }\end{array}$} & Eletroeletrônica* & \multirow{3}{*}{$17 \%$} & & \multirow{3}{*}{$17 \%$} & & \multirow{3}{*}{$18 \%$} & \\
\hline & Eletrônica & & & & & & \\
\hline & Eletrotécnica & & & & & & \\
\hline
\end{tabular}

Nota: * Estão destacados em cinza os cursos objetos desta pesquisa.

A partir destes dados, notou-se que a concentração feminina no Campus Cuiabá - Cel. Octayde Jorge da Silva foi inferior à masculina, nos três anos analisados (aumentando de 47\%, em 2017 para 48\%, em 2019). Outrossim, identificou-se que, na maioria dos casos, as meninas têm optado, cada vez mais, pelos cursos técnicos em Eventos e Secretariado (média de 82\% e 79\%, respectivamente). Estes cursos pertencem aos Eixos Tecnológicos "Turismo, Hospitalidade e Lazer" e "Gestão e Negócios". Entende-se assim, que, dos nove cursos ofertados pelo Campus, sete correspondem às áreas das Engenharias ou Tecnologias da Informação e Comunicação, em que a média da participação feminina é menor, se comparada à masculina.

A fim de ampliar a compreensão destes resultados buscou-se identificar, na Plataforma Nilo Peçanha (MEC, 2020), a representação feminina nos mesmos cursos, porém, em âmbito nacional (Tabela 2).

Tabela 2 - Concentração feminina, por ET, nos Institutos Federais, no Brasil (2017 a 2019)

\begin{tabular}{|c|c|c|c|c|}
\hline \multirow{2}{*}{ Eixo Tecnológico } & \multirow{2}{*}{ Curso Técnico } & 2017 & 2018 & 2019 \\
\hline & & (\%) Média & (\%) Média & (\%) Média \\
\hline Turismo, Hospitalidade e Lazer & Eventos & $68 \%$ & $75 \%$ & $78 \%$ \\
\hline Gestão e Negócios & Secretariado & $78 \%$ & $77 \%$ & $78 \%$ \\
\hline \multirow{2}{*}{ Infraestrutura } & Agrimensura* & \multirow{2}{*}{$48 \%$} & \multirow{2}{*}{$49 \%$} & \multirow{2}{*}{$51 \%$} \\
\hline & Edificações* & & & \\
\hline \multirow{2}{*}{ Informação e Comunicação } & Informática* & \multirow{2}{*}{$38 \%$} & \multirow{2}{*}{$39 \%$} & \multirow{2}{*}{$40 \%$} \\
\hline & Telecomunicações & & & \\
\hline \multirow{3}{*}{ Controle e Processos Industriais } & Eletroeletrônica* & \multirow{3}{*}{$28 \%$} & \multirow{3}{*}{$29 \%$} & \multirow{3}{*}{$31 \%$} \\
\hline & Eletrônica & & & \\
\hline & Eletrotécnica & & & \\
\hline
\end{tabular}

Nota: * Estão destacados em cinza os cursos objetos desta pesquisa.

Face ao exposto, percebe-se que os dados locais e nacionais, se assemelham, pois, nos Institutos Federais, os cursos técnicos em Eventos e Secretariado, integrados ao Ensino Médio, são ocupados majoritariamente por mulheres, com taxas superiores a $65 \%$. Com relação ao ET "Infraestrutura", nos anos de 2017 e 2018, a representação feminina foi menor nos cursos de Agrimensura e Edificações. Todavia, no ano de 2019, a presença feminina ultrapassou a masculina, com $51 \%$.

Sobre o ET "Informação e Comunicação", as taxas de ocupação feminina, nos cursos de Informática e Telecomunicações, variaram entre 38\% e 40\%. Já o ET "Controle e Processos 
Industriais", representado pelos cursos de Eletroeletrônica, Eletrônica e Eletrotécnica, foi o que apresentou a menor representatividade feminina, dentre os ETs e cursos analisados, variando de 28\%, em 2017, a 31\%, em 2019. Especificamente, nos Institutos Federais, os cursos técnicos integrados ao Ensino Médio foram compostos por $52 \%$ de meninos, contra $48 \%$ de meninas. Na Tabela 3, apresentam-se as taxas de ocupação das vagas em cada um dos 12 ETs.

\begin{tabular}{|c|c|c|c|c|c|c|}
\hline \multirow[b]{2}{*}{ Eixo Tecnológico } & \multicolumn{2}{|c|}{2017} & \multicolumn{2}{|c|}{2018} & \multicolumn{2}{|c|}{2019} \\
\hline & $\begin{array}{l}\text { Matrículas } \\
\text { ofertadas }\end{array}$ & (\%) Fem. & $\begin{array}{c}\text { Matrículas } \\
\text { ofertadas }\end{array}$ & $\begin{array}{l}(\%) \\
\text { Fem. }\end{array}$ & $\begin{array}{c}\text { Matrículas } \\
\text { ofertadas }\end{array}$ & $\begin{array}{l}(\%) \\
\text { Fem. }\end{array}$ \\
\hline Ambiente e Saúde & 13.619 & $58 \%$ & 14.993 & $60 \%$ & 16.190 & $62 \%$ \\
\hline Controle e Processos Industriais & 41.357 & $29 \%$ & 43.291 & $31 \%$ & 45.403 & $32 \%$ \\
\hline $\begin{array}{c}\text { Desenvolvimento Educacional e } \\
\text { Social }\end{array}$ & 4 & $75 \%$ & 49 & $61 \%$ & 70 & $71 \%$ \\
\hline Gestão e Negócios & 15.929 & $58 \%$ & 17.943 & $60 \%$ & 19.424 & $63 \%$ \\
\hline Informação e Comunicação & 46.100 & $38 \%$ & 49.267 & $39 \%$ & 51.891 & $40 \%$ \\
\hline Infraestrutura & 19.434 & $48 \%$ & 20.575 & $50 \%$ & 21.078 & $52 \%$ \\
\hline Produção Alimentícia & 10.294 & $60 \%$ & 10.839 & $63 \%$ & 11.599 & $65 \%$ \\
\hline Produção Cultural e Design & 2.948 & $61 \%$ & 3.539 & $63 \%$ & 3.963 & $64 \%$ \\
\hline Produção industrial & 15.871 & $54 \%$ & 16.376 & $56 \%$ & 16.715 & $59 \%$ \\
\hline Recursos Naturais & 39.369 & $44 \%$ & 40.589 & $46 \%$ & 40.912 & $49 \%$ \\
\hline Segurança & 1.477 & $60 \%$ & 1.612 & $63 \%$ & 1.782 & $63 \%$ \\
\hline Turismo, Hospitalidade e Lazer & 4.766 & $67 \%$ & 4.655 & $67 \%$ & 4.791 & $69 \%$ \\
\hline Total & 211.168 & $44 \%$ & 233.728 & $44 \%$ & 233.818 & $48 \%$ \\
\hline
\end{tabular}

Nota: Para uma melhor identificação, os ETs destacados em cinza, são os que foram ocupados, majoritariamente por meninas, em 2019.

Denota-se que, apesar das estudantes do Ensino Médio integrado serem maioria, em 9 dos 12 Eixos Tecnológicos da Rede Federal de Educação, estes cursos são os que possuem o menor número de vagas. Isto contribui para que a ocupação feminina seja minoritária, quando considerada a quantidade total de estudantes no EMI dos Institutos Federais. Apesar disso, ao se comparar as taxas de ocupação, de 2017 a 2019, percebe-se que a participação feminina aumentou cerca de 3\%, em todos os ETs analisados.

Embora o Inep (2020b; 2020c) aponte que, em âmbito nacional (55,9\%) e estadual (52,2\%), as matrículas da Educação Profissional foram ocupadas, em sua maioria, por meninas, percebese que, especificamente, no IFMT, Campus Cuiabá - Cel. Octayde Jorge da Silva, este fato não se repetiu, visto que, as meninas são minoria. Neste sentido, apurou-se que, um dos motivos desta disparidade, é que o Inep (2020b; 2020c) agregou, em seus estudos, os cursos técnicos das Redes Federal, Estadual, Municipal e Privada e considerou os cursos Técnicos Integrado ao Ensino Médio, Técnico Integrado - Educação de Jovens e Adultos (EJA), Técnico Concomitante, Técnico Subsequente e Normal/Magistério.

Deste modo, ressalta-se que o escopo desta pesquisa é explorar, apenas, a fração de dados que corresponde aos cursos técnicos integrados ao Ensino Médio do IFMT, Campus Cuiabá Cel. Octayde Jorge da Silva e, de modo complementar, apresentar os dados nacionais a fim de viabilizar uma análise expandida dos resultados.

Nesta direção, compreende-se que, tanto em âmbito local, quanto nacional, a presença feminina nos cursos técnicos integrados ao Ensino Médio está diretamente relacionada ao seu Eixo Tecnológico. Estas informações corroboram com inúmeras pesquisas e publicações, que vêm discutindo a equidade de gênero nas áreas da $\mathrm{C} \& \mathrm{~T}$, demonstrando que muitas delas ainda são representadas, majoritariamente, por homens. Sobre esta temática, García (2018) afirma que, 
embora existam estudos pontuais sobre a baixa representatividade feminina nas Ciências, datados desde o início do século XX, esta temática se expandiu ao final da década de 70 e, até mesmo, foi retratada pela Organização das Nações Unidas (ONU) na Convenção sobre a Eliminação de Todas as Formas de Discriminação contra as Mulheres ${ }^{5}$ (CEDAW).

Após a análise e discussão sobre o ingresso feminino nos cursos e do comparativo dos resultados (em âmbito local e nacional), investigou-se a interrupção dos cursos, por meio da evasão, conforme apresentado na próxima subseção.

\subsection{Sobre a interrupção do curso}

Os cursos pesquisados neste trabalho possuem tempo de duração distintos. Deste modo, é importante ressaltar que, tanto as estudantes que ingressaram nos cursos técnicos em Agrimensura e Edificações (a partir do ano de 2017), quanto as de Eletroeletrônica e Informática (a começar do ano de 2018), ainda estavam matriculadas no ano de 2019. Portanto, as taxas de evasão dos períodos destacados não são absolutas, uma vez que, poderão aumentar, até que as estudantes concluam o curso (Gráfico 2).

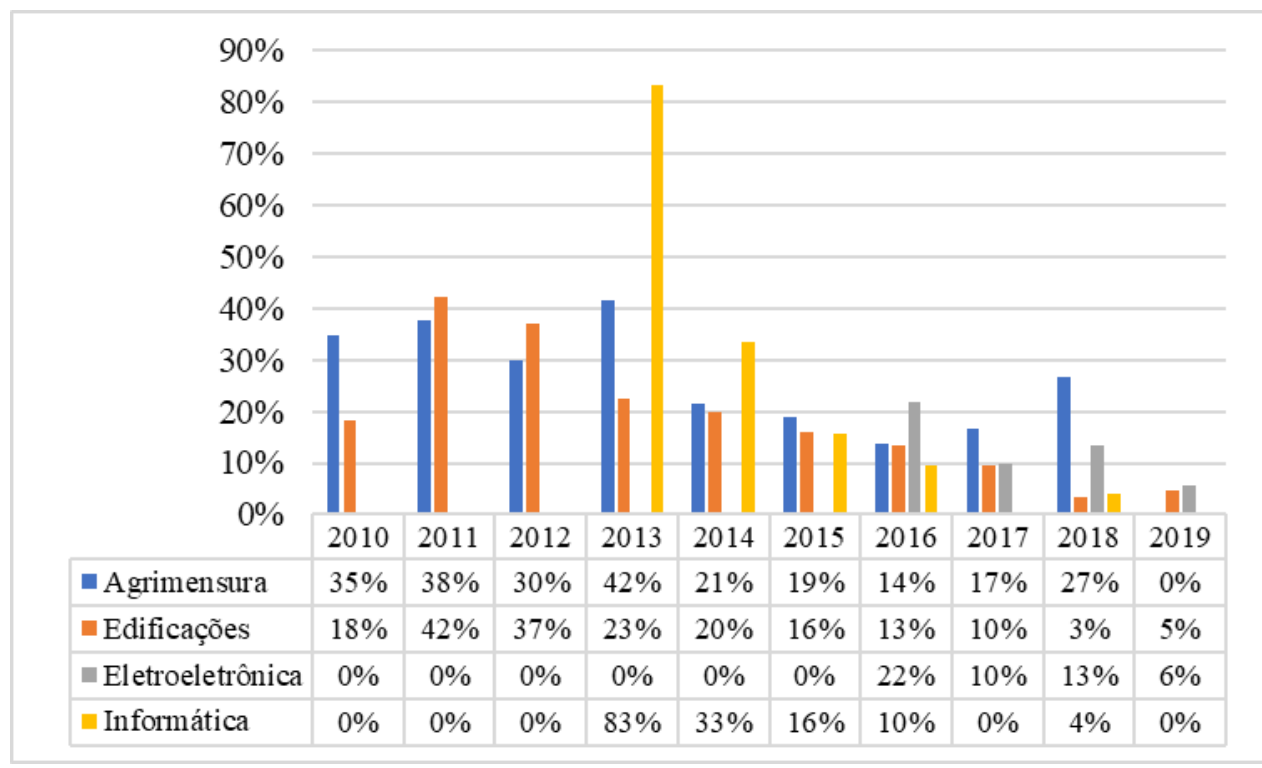

Gráfico 2 -Evasão feminina anual (2010-2019) do IFMT, Campus Cuiabá - Cel. Octayde Jorge da Silva Nota: O Gráfico retrata, apenas, a evasão feminina nos cursos objetos da pesquisa.

Ao se analisar o Gráfico 2, percebeu-se que a taxa média de evasão feminina, por curso, nos anos investigados, foi de: 24\% - Agrimensura; 19\% - Edificações; 13\% - Eletroeletrônica; e, $21 \%$ - Informática. Por conseguinte, observou-se uma taxa média geral de evasão das estudantes, de $19 \%$.

Apesar dos dados indicarem que o ingresso feminino, nestes cursos, é menor, eles sinalizam que, com exceção do curso Técnico em Informática, as meninas evadem menos. Isto pode ser confirmado ao se considerar que a taxa média de evasão masculina nos cursos é de: $36 \%$ Agrimensura; 26\% - Edificações; 18\% - Eletroeletrônica; e 19\% - Informática; sendo assim, a taxa média geral, de evasão masculina, foi de $25 \%$.

Particularmente, ao se investigar o curso Técnico em Informática, observou-se que a taxa de evasão, no ano de 2013, foi de $83 \%$, dentre as alunas ingressantes. Então, ao se aprofundar esta

\footnotetext{
5 Detalhes adicionais estão dispostos em: https:/www.unicef.org/brazil/convencao-sobre-eliminacao-de-todasformas-de-discriminacao-contra-mulheres.
} 
investigação, averiguou-se que, no referido ano, houve o ingresso de somente 6 alunas, sendo que 2 abandonaram o curso e 3 realizaram transferência externa.

Outro dado desvelado, é que o segundo maior pico de evasão de alunas foi de $42 \%$ e ocorreu nos cursos técnicos em Agrimensura (das 12 alunas ingressantes, 5 evadiram) e Edificações (das 19 alunas ingressantes, 8 evadiram). Ademais, os motivos mais recorrentes para a evasão feminina, nos cursos pesquisados, foram o abandono e a transferência externa (40\%), seguidos de cancelamento de matrícula (15\%) e transferência interna (4\%).

Embora o Inep (2020a) não tenha apresentado os dados com um recorte de gênero, ele apontou que, um dos fatores motivadores para a evasão, por meio da transferência externa, ocorreu mediante a perda de estudantes da EPT para a educação regular, uma vez que, aproximadamente $10 \%$ dos estudantes do Ensino Médio se formaram em um programa regular, depois de ingressarem em um curso profissional.

Face ao exposto, pôde-se verificar que os índices de evasão, dos cursos analisados, são expressivos, uma vez que o IFMT desenvolveu o "Plano Estratégico Institucional de Ações de Permanência e Êxito dos Estudantes do Instituto Federal de Mato Grosso" - PEIAPEE (IFMT, 2017), com o objetivo de elevar os índices de permanência e êxito dos estudantes, em todos os níveis e modalidades de ensino ofertadas no Instituto.

Neste documento, foram indicados diversos fatores que motivaram a evasão e que perpassam por questões: (i) de ordem individual - como reprovação e desmotivação para os estudos; (ii) internas à instituição - como a falta de acesso à assistência estudantil e a dificuldade com a avaliação praticada; e (iii) externas à instituição - como a distância da casa até o Instituto, aliada à dificuldade de transporte, dificuldade financeira, falta de apoio familiar, dentre outros.

Uma vez que os indicadores de evasão, nos cursos objetos desta pesquisa, foram apresentados, na próxima subseção discute-se a última etapa da jornada escolar, que é a conclusão de curso.

\subsection{Sobre a Conclusão do Curso}

Ao se quantificar as taxas de conclusão de curso, constatou-se que, em média, 70\% das alunas finalizaram o curso com êxito (Gráfico 3). Especificamente, as taxas médias de conclusão dos cursos técnicos foram: Agrimensura - 70\%; Edificações - 73\%; Eletroeletrônica - 70\% e Informática - 69\%. Nota-se que essas taxas superaram os dados desvelados pelo Inep (2020a), em que, no ano de 2018, no Brasil, somente 57\% dos estudantes da EPT concluíram o curso.

Igualmente, ao se comparar as taxas de conclusão, por gênero, averiguou-se que, com exceção do curso Técnico em Informática, os índices de conclusão feminina foram superiores ao masculino. A fim de atestar essa diferença, apresenta-se, adicionalmente, as taxas de conclusão ${ }^{6}$ masculina, por curso: Agrimensura - 56\%; Edificações - 71\%; Eletroeletrônica - 63\%; e Informática $-70 \%$; resultando em uma taxa média geral, de conclusão, de $65 \%$.

\footnotetext{
${ }^{6}$ As taxas masculinas foram apresentadas a título de comparação e não são consideradas no Gráfico 3.
} 


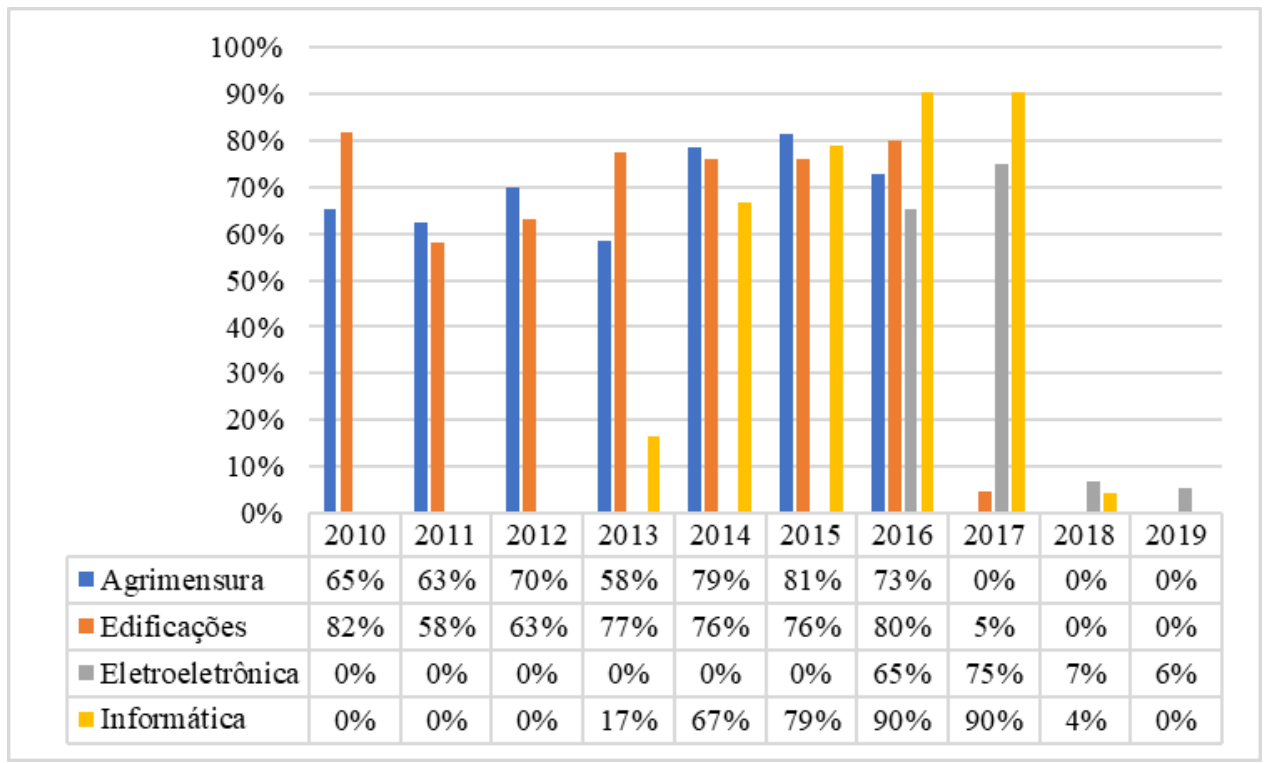

Gráfico 3 - Conclusão feminina anual (2010-2019) no IFMT, Campus Cuiabá - Cel. Octayde Jorge da Silva Notas:

(1) Para o cálculo da taxa média de conclusão feminina, dos cursos técnicos em Agrimensura e Edificações, considerou-se somente os anos entre 2010 e 2016, pois, estes cursos, possuem duração de quatro anos. Logo, as alunas que ingressaram a partir de 2017 ainda estavam em curso, em 2019.

(2) Da mesma forma, verificou-se que os cursos técnicos em Eletroeletrônica e Informática possuem duração de três anos; sendo assim, o cálculo da taxa média de conclusão foi realizado considerando os anos de 2016 e 2017, para o primeiro curso e, 2013 a 2017, para o segundo curso.

(3) Não foram considerados os desvios que ocorreram após os períodos destacados nas notas 1 e 2, pois se referem a estudantes que ingressaram na instituição/curso, a partir do $2^{\circ}$ ano do Ensino Médio, ou se trata de divergência de cadastro no sistema Q-Acadêmico.

Ao se analisar os cursos, separadamente, constatou-se que a taxa de conclusão das alunas ingressantes, no ano de 2013, no curso Técnico em Informática, foi de, apenas, 17\%. Basta relacionar este dado às taxas apresentadas sobre o ingresso e a evasão, no referido ano, para perceber que, das 6 alunas ingressantes, apenas uma concluiu o curso. Apesar disso, houve um incremento significativo, nos anos seguintes, e a taxa de conclusão, nos anos de 2018 e 2019 , elevou-se para $90 \%$.

Após apresentados e discutidos as taxas femininas de ingresso, interrupção e conclusão de curso, apresenta-se, na próxima seção, as considerações finais da pesquisa.

\section{Considerações Finais}

Este artigo reflete uma pesquisa de mestrado em andamento, que tem o objetivo de investigar e discutir como as experiências vivenciadas no Ensino Médio podem influenciar nas escolhas femininas, no que tange às suas decisões de formação, trabalho e carreira, e compartilhar estas descobertas em um programa de podcast ${ }^{7}$. Deste modo, este artigo apresenta os achados de uma das etapas da referida pesquisa e teve, como objetivo, investigar a representação feminina em alguns cursos técnicos integrados ao Ensino Médio da EPT, entre os anos de 2010 e 2019.

Com base nos resultados apresentados, observou-se que, em geral, o ingresso feminino nos cursos técnicos em Agrimensura, Edificações, Eletroeletrônica e Informática, integrados ao Ensino Médio da EPT, foi menor que o masculino. Percebe-se que, essa diferença, foi mais acentuada nos cursos técnicos em Eletroeletrônica e Informática. Inclusive, o primeiro curso

\footnotetext{
${ }^{7}$ O podcast intitulado "Ciência, Tecnologia e Meninas" foi desenvolvido como o Produto Educacional da referida pesquisa, no Mestrado Profissional em Educação Profissional e Tecnológica (ProfEPT), e pode ser ouvido em https://open.spotify.com/show/0Kf7v5foEykjU6Ybg8wbFM?si=K97VOzR8T8uNibCQtGcMow.
} 
apresentou uma diminuição de matrículas femininas, ao longo dos anos. Já os cursos técnicos em Agrimensura e Edificações, apresentaram uma maior representatividade feminina, ao passo que, em alguns anos, as meninas ocuparam mais da metade das vagas.

Depreendeu-se, também, que o mesmo não ocorreu nos cursos técnicos em Secretariado e Eventos. Nestes cursos, a ocupação feminina foi majoritária. Apesar destes cursos não terem sido selecionados como alvo da pesquisa, este comparativo foi fundamental para destacar as desigualdades da representação feminina em diferentes áreas do conhecimento.

Ao se expandir a análise da ocupação de matrículas, em âmbito nacional, ou seja, nos outros Institutos Federais do Brasil, foram obtidos resultados semelhantes aos do Campus Cuiabá Cel. Octayde Jorge da Silva. As meninas são minoria nas áreas dos cursos objetos desta pesquisa e, maioria, nos cursos de Secretariado e Eventos. Ademais, de forma geral, com exceção do curso Técnico em Informática, observou-se que as meninas têm evadido menos e as taxas de conclusão têm sido maiores.

Os achados desta pesquisa, quando articulados com os referenciais bibliográficos levantados, suscitam reflexões sobre a presença feminina na EPT, em especial, nos cursos técnicos integrados ao Ensino Médio, dos Institutos Federais do Brasil, voltados para as Ciências Exatas e Tecnologia da Informação. Além do mais, podem contribuir com outras áreas do conhecimento e outros níveis da Educação.

Desta forma, faz-se necessário registrar a importância de se desenvolver outros estudos, com abordagem qualitativa, sobre esta temática, e, assim, verificar os motivos que influenciam as estudantes na escolha dos cursos, a realidade vivenciada, bem como, as expectativas de formação e carreira. Estes estudos podem fomentar, por exemplo, a criação de ações voltadas para o desenvolvimento do interesse das estudantes, do Ensino Fundamental, pelas áreas das Ciências Exatas e Tecnologia da Informação, bem como propiciar às estudantes, dos cursos técnicos, experiências que impactem positivamente suas vivências nos cursos, de forma a promover a verticalização do ensino.

Por fim, acredita-se na importância de haver, cada vez mais, pesquisas com recorte de gênero, nos diferentes campos do conhecimento e nos diferentes níveis da Educação, de forma a propagar informações sobre como ocorrem as desigualdades de gênero e como mitigá-las.

\section{Referências}

CONFEA. (2021). Conselho Federal de Engenharia e Agronomia. Programa Mulher (2021 2023) Brasília-DF. Recuperado de https://www.confea.org.br/midias/confea cartilha mulher_2021_1.pdf

Freitas, L. B., \& da Luz, N. S. (2017). Gênero, Ciência e Tecnologia: estado da arte. cadernos Pagu, 49, e174908. doi: 10.1590/18094449201700490008 [GS Search]

García, M. I. G. (2018). Ciencia tecnología y género. Recuperado de https://dspacereva.conacyt.gov.py/xmlui-repo/handle/123456789/643 [GS Search]

García, M. I. G., \& Sedeño, E. P. (2002). Ciencia, tecnología y género. Revista Iberoamericana de Ciencia, Tecnología, Sociedad e Innovación, v. 2, p. 5, 2002. Recuperado de https://www.uv.es/ reguera/etica/genero-ciencia\%20.pdf [GS Search]

IFMT. (2017). Instituto Federal de Mato Grosso. Plano Estratégico Institucional de Ações de Permanência e Exito dos Estudantes do Instituto Federal de Mato Grosso PEIAPEE IFMT 2017. Recuperado de http://lrv.ifmt.edu.br/media/filer_public/d5/b8/d5b87d81-199640ef-8f6e-98804a8b4359/peiapee_instituto_federal_de mato_grosso.pdf 
IFMT. (2018). Instituto Federal de Mato Grosso. Plano de Desenvolvimento Institucional 2019 - 2023. Recuperado de http://pdi.ifmt.edu.br/media/filer public/b0/c5/b0c5bedc-811b-4f4cade8-0cb4a184a373/minuta pdi consultap 1.pdf

INEP. (2020a). Instituto Nacional de Estudos e Pesquisas Educacionais Anísio Teixeira. Panorama da educação: destaques do Education at a Glance 2020 [recurso eletrônico]. Recuperado de https://download.inep.gov.br/acoes_internacionais/eag/documentos/2020/Panorama_da_Ed ucacao 2020.pdf

INEP. (2020b). Instituto Nacional de Estudos e Pesquisas Educacionais Anísio Teixeira. Relatório do $3^{\circ}$ Ciclo de Monitoramento das Metas do Plano Nacional de Educação 2020 [recurso eletrônico]. Recuperado de https://anped.org.br/sites/default/files/images/relatorio do 3o_ciclo_de monitoramento_da s_metas_do_plano_nacional_de_educacao.pdf

INEP. (2020c). Instituto Nacional de Estudos e Pesquisas Educacionais Anísio Teixeira. Resumo Técnico: Censo da Educação Básica Estadual 2019 [recurso eletrônico]. Recuperado de http://portal.inep.gov.br/documents/186968/484154/Resumo+T\%C3\%A9cnico+do+Estado + do+Mato+Grosso+-

+ Censo+da+Educa $\% \mathrm{C} 3 \% \mathrm{~A} 7 \% \mathrm{C} 3 \% \mathrm{~A} 3 \mathrm{o}+\mathrm{B} \% \mathrm{C} 3 \% \mathrm{~A} 1$ sica+2019/2c0f07f3-fe37-47b9-adbd6754236ccd21?version $=1.1$

Kunze, N. (2009). O Surgimento da Rede Federal de Educação Profissional nos Primórdios do Regime Republicano Brasileiro. Revista Brasileira da Educação Profissional e Tecnológica, 2(2), 8-24. doi: 10.15628/rbept.2009.2939 [GS Search]

Lopes, S. F. P., \& Quirino, R. (2017). Relações de gênero na Educação Profissional e Tecnológica: as escolhas das alunas do CEFET-MG. In: Anais Eletrônicos do Seminário Internacional Fazendo Gênero 11 \& 13th Women's Worlds Congress (Anais Eletrônicos). Recuperado de http://www.en.wwc2017.eventos.dype.com.br/resources/anais/1499388721_ARQUIVO_Ar tigoCompletoSabrinaLopes.pdf [GS Search]

Louro, G. L. (2004). Mulheres na sala de aula. In: M. D. Priore (Org.), História das mulheres no Brasil, 469.

Marinho, G., Fagundes, S., \& Aguilar, C. (2019). Análise da participação feminina nos cursos técnicos e de graduação da área de Informática da Rede Federal de Educação Tecnológica e do Cefet/RJ, campus Nova Friburgo. In: Anais do XIII Women in Information Technology, (pp. 21-30). Porto Alegre: SBC. doi: 10.5753/wit.2019.6709 [GS Search]

MEC. (2020). Ministério da Educação. Plataforma Nilo Peçanha (Anos base 2017-2019). Recuperado de http://plataformanilopecanha.mec.gov.br/

Paiva, T. S. Z. N. (Autora). (2021, Março, 17). Ciência, Tecnologia e Meninas [podcast]. Recuperado

de https://open.spotify.com/show/0Kf7v5foEykjU6Ybg8wbFM?si=K97VOzR8T8uNibCQtGc Mow\&nd $=1$

Pereira, J., De Moura, L., Coelho, N., Montes, G., Magesti, I., \& Coelho, A. (2020). Uma Análise da Participação das Mulheres nos Cursos Técnico em Informática e Ciência da Computação do Instituto Federal do Sudeste de Minas Gerais. In: Anais do XIV Women in Information Technology, (pp. 139-148). Porto Alegre: SBC. doi: $\underline{10.5753 / \text { wit.2020.11284 }}$ [GS Search] 
Ribeiro, K., \& Maciel, C. (2020). Um Estudo sobre o Desenvolvimento da Carreira das Estudantes do Ensino Médio Integrado em Informática. In Anais dos Workshops do IX Congresso Brasileiro de Informática na Educação, (pp. 21-30). Porto Alegre: SBC. doi:10.5753/cbie.wcbie.2020.21 [GS Search]

Saavedra, L. (2009). Assimetrias de Género nas Escolhas Vocacionais, Guião de Educação, Género e Cidadania, Lisboa, p.121-130, jan. 2009. Recuperado de https://repositorium.sdum.uminho.pt/bitstream/1822/19997/1/Assimetrias\%20de $\% 20 \mathrm{~g} \% \mathrm{C} 3$ \%A9nero.pdf [GS Search]

Santana, T., Assis, I., Braga, R., \& Louzada, N. (2017). A importância de atividades de empoderamento feminino como forma de minimizar a evasão das mulheres nos cursos de Tecnologia da Informação. In: Anais do XI Women in Information Technology. Porto Alegre: SBC. doi: 10.5753/wit.2017.3407 [GS Search]

UNICEF. (1979). Fundo das Nações Unidas para a Infância. Convenção sobre a Eliminação de Todas as Formas de Discriminação Contra as Mulheres. Recuperado de https://www.unicef.org/brazil/convencao-sobre-eliminacao-de-todas-formas-dediscriminacao-contra-mulheres 